
\title{
28 Research Suare \\ Lymphocyte Subsets Analysis in Evaluating Prognosis of HIV Negative Patients with Pneumocystis Pneumonia
}

Fan Jin

Peking Union Medical College Hospital

Jing Xie

Peking Union Medical College Hospital

Huan-ling Wang (D 410713930@qq.com)

Peking Union Medical College Hospital

\section{Research Article}

Keywords: Pneumocystis peumonia, lymphocyte subsets, prognosis, immunosuppression, infectionandimmunity.

Posted Date: February 24th, 2021

DOI: https://doi.org/10.21203/rs.3.rs-225835/v1

License: (a) (1) This work is licensed under a Creative Commons Attribution 4.0 International License. Read Full License 
Lymphocyte subsets analysis in evaluating prognosis of HIV negative patients with pneumocystis pneumonia

Fan Jin ${ }^{1}$, MD, Jing Xie ${ }^{1}$, MD, Huan-ling Wang ${ }^{1,2}$, MD

${ }^{1}$ Dept. of Infectious Diseases, Peking Union Medical College Hospital, Chinese Academy of Medical Sciences \& Peking Union Medical College, Beijing 100730, China

${ }^{2}$ Clinical Pharmacology Research Center, Peking Union Medical College Hospital, Chinese Academy of Medical Sciences \& Peking Union Medical College, Beijing 100730, China

Corresponding author:

Huan-ling Wang,

Peking Union Medical College Hospital, Chinese Academy of Medical Sciences \& Peking Union Medical College

Address: No.1 Shuaifuyuan, Wangfujing, Dongcheng District, Beijing,China 100730

E-mail: wanghuanling@pumch.cn Tel: +86-69155001 


\begin{abstract}
Objectives

We analyzed the peripheral blood lymphocyte subsets of human immunodeficiency virus (HIV) negative patients infected with pneumocystis pneumonia (PCP), aimed to find out the relationship between the levels of different types of lymphocytes with the prognosis of patients.
\end{abstract}

\title{
Methods
}

We retrospectively reviewed HIV negative patients with PCP diagnosed in our department, all the eligible patients underwent lymphocyte subsets analysis on admission.

\section{Results}

A total of $88 \mathrm{HIV}$ negative PCP patients were enrolled in the study. In univariate analyses, low CD4+ T cell count, low CD8+ T cell count, and low natural killer cell (NK cell) count were associated with in-hospital mortality. CD8+ $\mathrm{T}$ cell count $\leq 300 / \mu \mathrm{L}$ was found to be an independent risk factor for poor prognosis in multivariate logistical regression analysis $(p=0.015, \quad O R=11.526$, 95\% $\mathrm{CI}=1.597-83.158)$. Although low $\mathrm{CD} 4+\mathrm{T}$ cell and NK cell counts were not independent risk factors, the mortality rates of PCP patients decreased sequentially with the increased levels of CD4+ T cell and NK cell counts.

\section{Conclusion}

The immunity process of Pneumocystis jirovecii infection is complex and crucial. We proposed that lymphocyte subsets give clinicians better understandings of patients 
immune status, early identification of potential lethal patients and decision making, such as adjusting immunosuppressive regimen and choosing appropriate patient monitoring level.

\section{Key words}

Pneumocystis peumonia; lymphocyte subsets; prognosis; immunosuppression; infection and immunity.

\section{Introduction}

Pneumocystis pneumonia (PCP) is a life-threatening interstitial pneumonia caused by Pneumocystis jirovecii ( $P$. jirovecii) among immunocompromised patients [1-2]. PCP has long been known for its high prevalence in Acquired Immunodeficiency Deficiency Syndrome (AIDS) patients [3], but the incidence of PCP in human immunodeficiency virus (HIV) positive patients was decreased largely due to the broader use of highly active antiretroviral therapy (HAART) and trimethoprim-sulfamethoxazole (TMP/SMZ) prophylaxis when the CD4+ T cell count is $<200 / \mu \mathrm{L}$ [4-5]. Recently, PCP has been frequently diagnosed in HIV negative patients as immunosuppressive regimens are being increasingly used in a wide range of patients. Main underlying conditions of PCP in non-HIV infected patients are haematological malignancies, followed by solid tumours, inflammatory diseases, solid organ transplant, etc [6-7]. The mortality rate among patients with PCP in this population is $30-60 \%$ [8]. HIV negative PCP patients are more likely to have acute 
onsets, more severe symptoms, and worse prognosis compared with HIV positive patients [8]. Identifying potential prognostic factors in PCP patients could help clinicians choose appropriate treatment strategy and monitoring level.

The major portion of the PCP process is a consequence of the host inflammatory response to apparent infection with $P$. jirovecii, rather than a direct tissue damage from P. jirovecii [9-10]. Since PCP is a type of opportunistic infections (OIs), lymphocyte subsets can be used as important indicator detecting in the immune function of the body, and as clinical assistant diagnosis of some infectious diseases, which is of great significance to analyze the pathogenesis, observe the curative effect, and predict the prognosis [12]. T cells are known to be involved in suppression of autoimmune response and hyperinflammation mediated by CD4+ T cells [13]. B cells and NK cells are critical for effective CD4+ T cell response to control Pneumocystis infection [14]. In this article, we mainly analyzed the peripheral blood lymphocyte subsets of HIV negative PCP patients, aimed to find out the influence of $\mathrm{T}$ lymphocyte, B lymphocyte and natural killer cell (NK cell) counts on the prognosis of patients.

\section{Material and methods}

\subsection{Patients selection}

We carried out an observational retrospectively study from 2012 to 2018 in the Peking Union Medical College Hospital (PUMCH), a 2000-bed tertiary care center in Beijing, China. PCP diagnosis was based on consensus guidelines, requiring either $P$. 
jirovecii microorganisms in respiratory samples by microscopic examination or both positive tests for $P$. jirovecii DNA polymerase chain reaction (PCR) using respiratory samples and an increased level of serum 1,3- $\beta$-D-glucan ( $\beta D G)$ [15]. Patients were eligible for enrollment if they fulfilled all the following criteria: (1) being older than 18 years of age; (2) being HIV negative; (3) undergoing lymphocyte subsets analysis within one week after admission. The follow-up time was more than 3 months. We excluded patients who had lost follow-up and incomplete data.

This retrospective study was reviewed and approved by the Institutional Review Board (IRB) of PUMCH. The researches does not interfere with the treatment plan of patients, and they will protect the information of patients from being disclosed. The study met the IRB's minimal risk waiver criteria, therefore, the requirement to obtain informed consent from each patient was waived.

\subsection{Technical information}

We used primers to amplify the mitochondrial large subunit rRNA (mtLSUrRNA) gene of $P$. jirovecii in PCR test. The sequences of major surface glycoprotein (MSG), primer for the $P$. jirovecii target gene were MSG-fw, 5'-CTTAAAATAAATAATCAGACTATGTGCGATAAG-3', and MSG-rv, 5'-GGAGCTTTAATTACTTTTTTCTGGC-3'. A dual labeled fluorescence resonance energy transfer (FRET) hydrolysis probe (MSG-probe 5'-FAM-TAGATAGTCGAAAGGGAAA-MGE-3') was used for detection. The cycle threshold $(\mathrm{Ct})$ value was checked for positive samples, and defined as the replicated 
cycle number at which the fluorescence generated within a reaction crossed the fluorescence threshold. The positive PCR result in our study was defined as Ct value $\leq 37[16]$

Lymphocyte subsets analysis was performed in the clinical hematology laboratory by trained personal using FACScan flow cytometer (Beckman-Coulter, USA). The monoclonal antibodies used in this study (purchased from Beckman-Coulter and Immunotech, USA) included PEcy5- CD4/PE-CD45RA/FITC-CD62L (memory and naive markers), PEcy5-CD4/FITC-CD28 (functional marker), PEcy5-CD8/PE-CD38/FITC-HLA-DR (activation markers), and PEcy5-CD4/PECD8/FITC-CD3 (CD4+/CD8+T cell count).

\subsection{Data collection}

All medical records were reviewed retrospectively using standardized research protocol. The chart review included demographic characteristics, underling diseases, laboratory data, presence of co-infection, immuosuppressive treatments, the dosage and exposure time of corticosteroids treatment, and time of symptoms onset to anti-PCP treatments. Additionally, need for Intensive Care Unit (ICU) and mechanical ventilation (MV), and clinical outcomes were recorded for patients. Co-infections, such as bacteria, Candida, Aspergillus, cytomegalovirus, and Epstein-Barr virus were also evaluated and recorded. PCP-relevant clinical symptoms occurring $>48$ hours after hospitalization was considered as hospital-associated PCP. Survival was defined as being alive 3 months after symptoms onset. In order to determine the best critical 
threshold of these cell counts for prognosis, we constructed the ROC curves to investigate the predictors of in-hospital mortality.

\subsection{Statistical Analysis}

Categorical variables were analyzed by Chi-square test or with Fisher's exact test, as appropriate. Continuous variables was analyzed using WilCoxon signed-rank test. The receiver operating characteristic (ROC) curve showed the tradeoff between the true detections and false detections in univariate analysis to predict the prognosis of PCP. On each ROC curve, we calculated and selected the point with the largest Youden index $($ Youden index $=$ sensitivity + specificity -1$)$ as the cut-off threshold To identify predictors of in-hospital mortality or survival we applied univariate and multivariate logistical regression analyses and Cox regression hazards models. Consequently, both odds ratio (OR) and hazard ratio (HR) estimates were reported. Confidence intervals (CI) were calculated with coverage of $95 \%$. In addition, we calculated the time of symptom onset to all-cause mortality from multivariable Cox regression models. All statistical analyses were performed using SPSS 22.0 (SPSS Inc., Chicago, IL, USA). P-value $<0.05$ were considered statistically significant.

\section{Results}

\subsection{Baseline patient characteristics}

180 HIV negative patients had positive PCR and/or Grocott's methenamine silver staining (GMS staining) resulted from sputum or bronchoalveolar lavage (BAL). A 
total of 88 patients met the inclusion criteria (Table 1). The median age of the patients was 57 years old and $42 \%$ of them were male. The most common underlying disease was inflammatory disease $(\mathrm{n}=61)$, others included, hematology disorder, solid cancer and so on. $34 \%$ of the patients had underlying lung disease such as interstitial lung disease caused by inflammatory diseases, lung metastasis caused by solid tumors, and idiopathic pulmonary fibrosis. Immunosuppressive regimens consisted of mainly a combination of corticosteroid (CS) and immunosuppressive drugs, the median CS exposure time of patients was 3 months (interquartile range from 2 to 42 months). The majority of patients were complicated with virus infection (63\%), followed by bacteria $(30 \%)$ and fungus $(18 \%) .14 \%$ of the patients were considered to have hospital-associated PCP. Patients with PCP had significantly lower immune cell counts (including CD19+ B cells, CD16+CD56+ NK cells, and CD3+ T cells) and ratio of $\mathrm{CD} 4+/ \mathrm{CD} 8+$ (median ratio was 0.6$)$.

Table 1. Clinical characteristics, management, and outcomes of in HIV negative patients with PJP.

\begin{tabular}{lllll}
\hline & $\begin{array}{l}\text { Total } \\
(\mathrm{n}=88)\end{array}$ & $\begin{array}{l}\text { Survivors } \\
(\mathrm{n}=49)\end{array}$ & $\begin{array}{l}\text { Non-survivors } \\
(\mathrm{n}=39)\end{array}$ & $\begin{array}{l}\text { P-value } \\
\text { Demographics }\end{array}$ \\
$\begin{array}{llll}\text { Age, years } \\
\text { Sex (male) }\end{array}$ & $58(42-64)$ & $58(48-64)$ & $55(40-63)$ & 0.559 \\
Underlying lung disease & $37(42 \%)$ & $22(45 \%)$ & $15(39 \%)$ & 0.543 \\
Immunosuppressive conditions & $30(34 \%)$ & $12(24 \%)$ & $18(49 \%)$ & 0.033 \\
Jnflammatory diseases & & & $29(74 \%)$ & 0.360 \\
Hematologic disorder & $61(69 \%)$ & $32(66 \%)$ & $2(5 \%)$ & 0.609 \\
Hematologic malignancy & $6(7 \%)$ & $4(8 \%)$ & $4(10 \%)$ & 0.098 \\
\hline
\end{tabular}




$\begin{array}{llllr}\text { Solid cancer } & 8(9 \%) & 5(10 \%) & 3(8 \%) & 0.684 \\ \text { Other disease* } & 8(9 \%) & 7(14 \%) & 1(3 \%) & 0.057\end{array}$

Laboratory values on admission

Albumin, g/L

LDH, U/L

$\mathrm{PaO} 2, \mathrm{mmHg}$

$\mathrm{D}(\mathrm{A}-\mathrm{a}) \mathrm{O} 2, \mathrm{mmHg}$

Creatinine, $\mathrm{mg} / \mathrm{d}$

CRP, mg/dL

Flow cytometry on admission

Lymphocyte count $(\times 106 \mathrm{~g} / \mathrm{L})$

CD19+ B, cell $/ \mu \mathrm{L}$

CD16+CD56+ NK, cell/ $\mu \mathrm{L}$

$\mathrm{CD} 3+\mathrm{T}$, cell $/ \mu \mathrm{L}$

CD4+ T, cell $/ \mu \mathrm{L}$

$\mathrm{CD} 8+\mathrm{T}$, cell $/ \mu \mathrm{L}$

CD4+/CD8+ ratio

Immuosuppressive conditions

CS exposure time, month

$\mathrm{CS} \leq 40 \mathrm{mg} / \mathrm{d}$

$500 \mathrm{mg} / \mathrm{d}>\mathrm{CS} \geq 80 \mathrm{mg} / \mathrm{d}$

$\mathrm{CS} \geq 500 \mathrm{mg} / \mathrm{d}$

Non-steroidal immunosuppressive therapy

Cyclophosphamide

Methotrexate

Mycophenolate mofetil

Azathioprine

Leflunomide

Tacrolimus

$\begin{array}{llll}27(24-31) & 29(25-32) & 26(24-29) & 0.027 \\ 566(422-718) & 460(332-612) & 656(557-946) & <0.001 \\ 53(46-59) & 56(47-61) & 51(39-59) & 0.174 \\ 60(52-68) & 60(53-66) & 61(52-69) & 0.157 \\ 68(53-110) & 65(53-94) & 69(54-115) & 0.146 \\ 12(6-80) & 9(5-63) & 21(6-114) & 0.629\end{array}$

$360(237-711)$

499 (280-1032)

301 (160-406)

0.162

36 (11-102)

55 (18-141)

$34(8-64)$

0.346

34 (14-73)

$50(26-83)$

$22(7-46)$

0.014

297 (174-662)

517 (234-871)

209 (138-330)

$<0.001$

$120(48-232)$

149 (82-314)

$81(35-145)$

0.004

151 (78-356)

239 (101-455)

114 (59-204)

$<0.001$

$0.53(0.31-1.38)$

$0.6(0.3-1.4)$

$0.6(0.4-1.5)$

0.971
$3(2-42)$

$56(64 \%)$

$5(6 \%)$

$8(9 \%)$

$33(38 \%)$

$9(10 \%)$

$8(9 \%)$

$2(2 \%)$

$8(9 \%)$

$5(6 \%)$
4 (2-22)

$30(61 \%)$

2 (4\%)

2 (4\%)

$17(35 \%)$

$4(8 \%)$

$6(12 \%)$

$1(2 \%)$

4 (8\%)

2 (4\%)
$3(2-53)$

$26(67 \%)$

$3(8 \%)$

$6(15 \%)$
0.067

0.490

0.598

0.467

0.542

0.474

$5(13 \%)$

0.249

2 (5\%)

0.870

$1(3 \%)$

0.734

$4(10 \%)$

0.467 


\begin{tabular}{|c|c|c|c|c|}
\hline $\mathrm{CS}+$ immunosuppressive drug & $52(59 \%)$ & $27(55 \%)$ & $25(64 \%)$ & 0.394 \\
\hline Chemotherapy & $14(16 \%)$ & $6(12 \%)$ & $8(21 \%)$ & 0.292 \\
\hline \multicolumn{5}{|l|}{ Imaging manifestations } \\
\hline Ground glass opacity & $69(78 \%)$ & $38(79 \%)$ & $31(84 \%)$ & 0.826 \\
\hline Consolidations & $20(23 \%)$ & $10(21 \%)$ & $10(27 \%)$ & 0.561 \\
\hline \multicolumn{5}{|l|}{ Co-infections } \\
\hline Bacterial & $26(30 \%)$ & $13(27 \%)$ & $12(31 \%)$ & 0.661 \\
\hline Viral & $55(63 \%)$ & $30(61 \%)$ & $25(64 \%)$ & 0.780 \\
\hline Fungal & $16(18 \%)$ & $10(20 \%)$ & $6(15 \%)$ & 0.544 \\
\hline \multicolumn{5}{|l|}{ Clinical progression } \\
\hline Symptoms onset to treatment, days & $7(4-15)$ & $8(5-16)$ & $7(3-12)$ & 0.359 \\
\hline Mechanical ventilation & $44(50 \%)$ & $10(20 \%)$ & $34(87 \%)$ & $<0.001$ \\
\hline Hospital-associated PCP & $12(14 \%)$ & $6(12 \%)$ & $6(15 \%)$ & 0.670 \\
\hline
\end{tabular}

*Others: Severe combined immunodeficiency, drug-induced liver damage, ulcerative colitis, idiopathic pulmonary fibrosis and solid organ transplantation.

Data are presented as median (interquartile range) and $\mathrm{n}(\%)$.

\subsection{Clinical parameters and outcomes}

As shown in Table $1,44 \%(n=39)$ of HIV negative patients infected with PCP died within 3 months after symptoms onset. No differences were noted in age, sex, previous use of chemotherapy, immunosuppresive regimens, the dosage and exposure time of CS treatment, co-infections (bacteria, virus, and fungus), treatment delay (symptoms onset to treatment), and hospital-associated PCP between survivors and non-survivors. The mortality rate of patients with autoimmune diseases was highest (69\%). Compared with survivors, non-survivors had significantly lower albumin levels $(\mathrm{p}=0.027)$, higher LDH levels $(\mathrm{p}<0.001)$, and higher demanding for mechanical 
ventilation $(p<0.001)$. Besides, more non-survivors had underlying lung diseases $(p=0.033)$. As for lymphocyte subsets, non-survivors had significantly lower NK cell count ( 22 vs. 50 cell $/ \mu \mathrm{L}, \mathrm{p}=0.014)$, lower $\mathrm{CD} 4+\mathrm{T}$ cell count ( 81 vs. 149 cell $/ \mu \mathrm{L}$, $\mathrm{p}=0.004)$ and lower $\mathrm{CD} 8+\mathrm{T}$ cell count $(114$ vs. 239 cell $/ \mu \mathrm{L}, \mathrm{p}<0.001)$. There was no significant difference in B cell count between survivors and non-survivors (55 vs. 34 cell $/ \mu \mathrm{L}, \mathrm{p}=0.346)$.

\subsection{Lymphocyte subsets analysis and prognosis}

After compared with survivors through univariate analysis, we found that the non-survivors had lower CD4+ T, CD8+ T, and NK cell counts (Table 2). As shown in Figure 1, the area under the curve (AUC) of CD8+ T cell count was $0.728(\mathrm{p}<0.001)$, indicating that CD8+ T cell count was an important predictor of in-hospital mortality. The optimal cutoff for CD8+ T cell count was determined to be $300 / \mu \mathrm{L}$, specificity/sensitivity was $0.95 / 0.47$. The area under the CD4+ $\mathrm{T}$ cell count curve $(p=0.020)$ and NK cell count $(p=0.005)$ were slightly smaller. The optimal cutoff for CD4+ T cell count was determined at $100 / \mu \mathrm{L}$ with a specificity/sensitivity of $0.71 / 0.67$. The optimal cutoff for NK cell count was determined at $25 / \mu \mathrm{L}$ with a specificity/sensitivity of $0.68 / 0.79$.

Table 2. Characteristics associated with mortality in a univariate and multivariate analysis in HIV negative patients with PJP.

\begin{tabular}{llllll}
\hline Characteristics & \multicolumn{2}{l}{ Univariate analysis } & & \multicolumn{2}{l}{ Multivariate analysis } \\
\cline { 2 - 3 } \cline { 4 - 6 } & OR $(95 \% \mathrm{CI})$ & P-value & & OR $(95 \% \mathrm{CI})$ & P-value \\
\hline
\end{tabular}


Underlying lung disease
no
1
1
yes
$2.643(1.068-1.068)$
0.035
$2.134(0.501-9.089)$
0.305

Albumin

$\begin{array}{ll}\geq 30 & 1 \\ <30 & 2.500(0.981-6.371) \quad 0.055\end{array}$

LDH, U/L

$\begin{array}{ll}<600 & 1 \\ \geq 600 & 2.196(0.928-5.198)\end{array}$

CD4+ T, cell $/ \mu \mathrm{L}$
$\geq 100$
1
1
$<100$
$3.793(1.341-10.729) \quad 0.012$
$0.255(0.040-1.646)$
0.151

$\mathrm{CD} 8+\mathrm{T}$, cell $/ \mu \mathrm{L}$

$\begin{array}{lllll}\geq 300 & 1 & 1 & \\ <300 & 10.615(2.880-39.130) & <0.001 & 11.526(1.597-83.158) & 0.015\end{array}$

CD16+CD56+ NK, cell $/ \mu \mathrm{L}$
$\geq 25$
1
1
$<25$
$3.990(1.609-9.893) \quad 0.003$
$2.168(0.561-8.379) \quad 0.262$

Mechanical ventilation
no
1
1
yes
$26.520(8.248-85.265) \quad<0.001$
$33.578(8.056-139.950) \quad<0.001$

Figure 1. ROC curves for the predictors of in-hospital mortality for CD4+ T, CD8+ T, and NK cell counts.
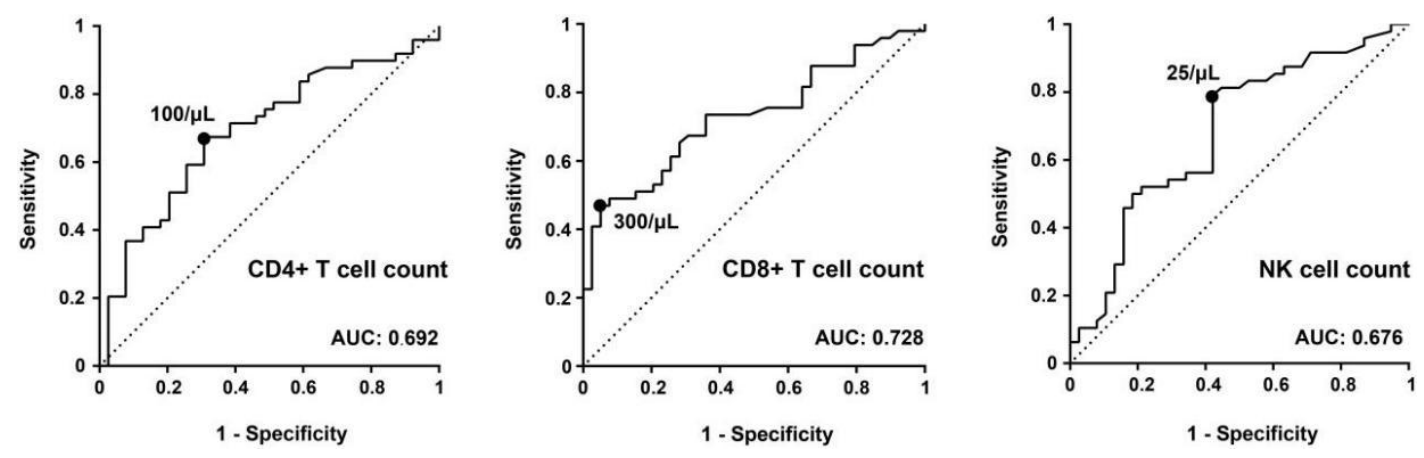
The 3-month mortality rates determined according to the levels of CD4+ T, CD8+ T, and NK cell counts over different ranges were shown in Figure 2. We found that the mortality rates of patients decreased sequentially in the four ranges of CD4+ $\mathrm{T}$ cell count from $0-100 / \mu \mathrm{L}, 101-200 / \mu \mathrm{L}, 201-300 / \mu \mathrm{L}$, and $>300 / \mu \mathrm{L}$, they were $63 \%, 38 \%$, $33 \%$ and $18 \%$. Similarly, the mortality rates of patients with NK cell count from $0-25 / \mu \mathrm{L}, 26-50 / \mu \mathrm{L}, 51-100 / \mu \mathrm{L}$, and $>100 / \mu \mathrm{L}$ decreased sequentially $(65 \%, 40 \%, 27 \%$ and $26 \%$ ). The mortality rates were almost the same in patients with CD8+ $\mathrm{T}$ cell count from $0-100 / \mu \mathrm{L}, 101-200 / \mu \mathrm{L}$, and $201-300 / \mu \mathrm{L}$. But for patients with CD8+ T cell count $>300 / \mu \mathrm{L}$, the mortality rate dropped by more than $40 \%$.

Figure 2. The 3-month mortality rates determined according to the levels of CD4+ T, CD8+ T, and NK cell counts over different ranges.

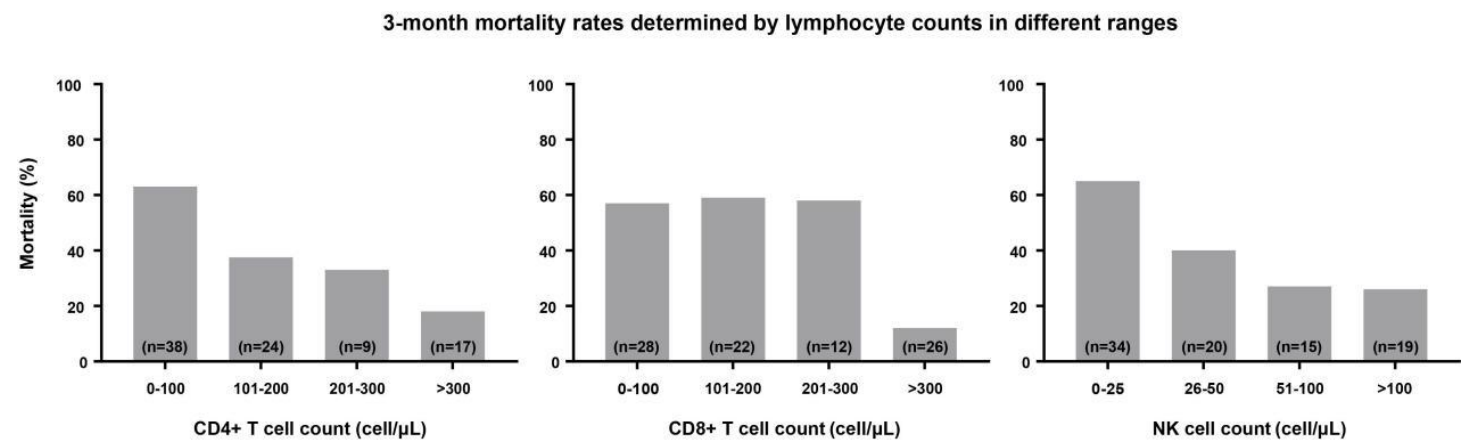

3.4. Independent predictors of mortality in PCP patients

Prognostic factors of 3-month mortality were explored with logistic regression. Table 2 showed the results of multivariate analysis. In the multivariate analysis, corrections were made for underlying lung disease, need for mechanical ventilation, CD4+ T, CD8+ T, and NK cell counts. In HIV negative patients with PCP, the 
presence of $\mathrm{CD} 8+\mathrm{T}$ cell count $\leq 300 / \mu \mathrm{L}(\mathrm{p}=0.015, \mathrm{OR}=11.526,95 \% \mathrm{CI}=1.597-83.158)$, and demand of mechanical ventilation $(\mathrm{p}<0.001, \mathrm{OR}=33.578,95 \% \mathrm{CI}=8.056-139.950)$ were independent predictors of 3-month all cause mortality.

In addition, we performed a Cox regression hazards model to further understand the interdependence of $\mathrm{CD} 8+\mathrm{T}$ cells as a determinant of 3-month mortality. The survival probability curve is shown in Figure 3. The result further confirmed that low CD8 $+\mathrm{T}$ cell count was significantly associated with high mortality $(\mathrm{p}=0.001$, $\mathrm{HR}=6.799,95 \% \mathrm{CI}=2.090-22.121)$.

Figure 3. Survival curve for the Cox regression hazards model for the relationship between CD8+ T cell count and 3-month mortality.

Survival curve for the Cox regression model

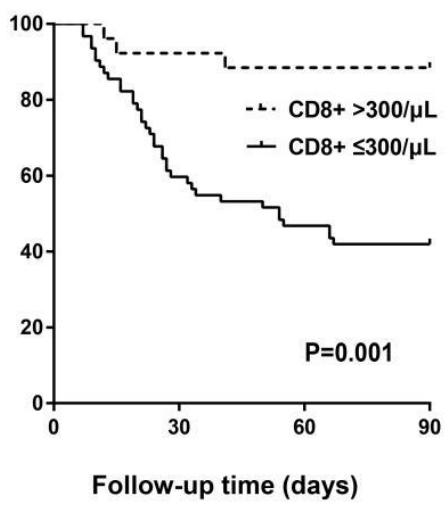

\section{Discussion}

In this study, all 88 HIV negative patients with PCP had long-term and varying degrees of immunosuppression, mostly manifested as diffuse lymphocytes depletion. Grouped by the threshold from ROC analysis, we identified CD8 $+\mathrm{T}$ cell 
count $<300 / \mu \mathrm{L}$ as an independent risk factor of death in PCP patients. Additionally, the HR of CD8+ T cell count $<300 / \mu \mathrm{L}$ was 6.799 associated with 3-month mortality. Although low CD4+ T cell and NK cell counts were not independent risk factors for death, the mortality rates of PCP patients decreased sequentially with the increased level of them.

With the HIV epidemic in the 1980s, PCP was known as a most common OIs among AIDS patients. In recent years, immunosuppressive therapy and biological agents, especially when used in combination, increase risk of infection by opportunistic pathogens such as $P$. jiroveci [17]. It was recognized that low CD4+ T cell count is a risk factor for death of HIV positive patients infected with PCP in many large retrospective cohort studies [18-22], and lymphopenia is a poor prognostic factor in HIV negative patients with PCP infection [23]. However, the prognostic value of lymphocyte subsets in HIV negative PCP patients remains unclear. In two small retrospective studies, one revealed that CD4+ T cell count $<200 / \mu \mathrm{L}$ in kidney transplant recipients was a poor prognostic factor for PCP infection [24], and the other showed that CD8 $+\mathrm{T}$ cell count $<160 / \mu \mathrm{L}$ was strongly associated with mortality in autoimmune diseases patients with PCP [25]. However, we identified CD8+ T cell count $<300 / \mu \mathrm{L}$ as an independent risk factor of death in HIV negative PCP patients. In addition, NK cell count was included in the analysis for the first time.

The pathogenesis and prognosis of opportunistic infection are closely related to immune status, the importance of lymphocytes in combatting $P$. jirovecii infection has been recognized. Lymphocytes participate in host defense by regulating other immune 
cells, producing antibodies against pathogens (B cells) and killing organisms (cytotoxic CD8+ $\mathrm{T}$ cells and $\mathrm{NK}$ cells) [26]. CD4+ $\mathrm{T}$ cells can promote the proliferation and differentiation of B cells, $\mathrm{T}$ cells, and other immune cells, coordinate the interaction between immune cells, and play a central role in coordinating host defense mechanisms. CD8+ T cells includes inhibitory T cells and killer T cells [27]. If the inflammatory response is driven by CD4+ T cells without sufficient inhibitory activity from CD8+ $\mathrm{T}$ cells, it will cause an effective but excessive inflammatory response similar to immune restoration disease (IRD), and the elimination of pathogens will take severe lung injury as a cost [28]. Dysregulation of CD4+ T cells can lead to a decrease in their ability to assist CD8+ T cells, which in turn leads to a reduction in the killing and dissolving function of $\mathrm{CD} 8+\mathrm{T}$ cells, that is, the negative regulation of the immune response takes a comparative advantage. In our study, CD8+ $\mathrm{T}$ cell count $<300 / \mu \mathrm{L}$ was an independent risk factor of death in PCP patients. Although CD4+ T cells play a central role in coordinating the host defenses against $P$. jirovecii, the inhibition and cytotoxic effects of $\mathrm{CD} 8+\mathrm{T}$ cells seem to be critical to control and terminate the infection.

The level of NK cell count was also associated with the prognosis of PCP patients. Most striking of our findings was the progressive increase in mortality as NK cell count decreased from $>100 / \mu \mathrm{L}(26 \%$ mortality) to $<25 / \mu \mathrm{L}$ (65\% mortality). NK cells are an important component of immune defense against $P$. jirovecii infection, by releasing IFN-g, granzyme, perforin and by direct microbial activity [29, 30]. Recent studies have demonstrated that NK cells directly regulate adaptive immune responses 
through the interaction of CD4+ T cells [31-33]. Therefore, we believe that the NK cell count has certain prognostic value for PCP patients. Being aware of the importance of NK cells in combatting $P$. jirovecii infection, it is necessary for us to further clarify the immunity process of $P$. jirovecii infection in human.

We usually believe that the longer exposure time and higher dose of the immunosuppressive therapy, the more severe the degree of immunosuppression is for patients. However, in our study, no association was found between the prognosis of PCP and type of immunosuppresive regimens, the dosage or exposure time of CS. It is implied that the prognosis of PCP patients can not be simply reflected by immunosuppressive therapy. Our study revealed low CD4+ T cell, CD8+ T cell, and NK cell counts were related to poor prognosis of PCP, especially CD8+ T cell. Therefore, for patients receiving high-dose immunosuppressive therapy, lymphocyte subsets analysis is of great significance for clinicians to assess the degree of the immunosuppression. In some studies, CD4+ T cell count $<200 / \mathrm{mm}^{3}$ was taken as the prevention strategy of PCP in HIV negative patients according to HIV [34]. Our study demonstrates that several patients have CD4+ T $>200 / \mathrm{mm}^{3}$, and CD8 $+\mathrm{T}$ and NK cells are associated with the prognosis of patients. Because there are variety changes of immune system in HIV negative patients, it cannot be described by a single CD4+ T cell count. Therefore, the CD4+ T cell count should not be the only indication of prophylaxis in HIV negative patients, the levels of CD8+ T and NK cell counts should also be considered.

For HIV positive patients with severe PCP, a large amount of medical based 
evidence showed that corticosteroid as an adjuvant treatment can reduce the mortality [35]. However, for HIV negative PCP patients, due to the non-specific anti-inflammatory effects and serious side effects of corticosteroid, the application in immunocompromised individuals is still controversial [36]. Therefore, alternative treatments for HIV negative patients with PCP need to be more specific. Recent studies have suggested that the CD4+CD25+ T cells [37] and CD40 ligand [31] seem to be helpful in the regulation of immunity to $P$. jirovecii infection. CD4+CD25+ T cells seem to suppress proliferation and cytokine production, to be determined in limiting the occurrence of the immune reconstitution disease [38]. CD40L+ effector memory $\mathrm{CD} 4+\mathrm{T}$ cells can control the reactivation and maintain the response of $\mathrm{NK}$ cells through IL-2 production and promote secretion of chemokine ligand-10 (CXCL 10) from dendritic cells [39]. In murine experimental model, CD40 ligand [40-42] and anti-CD3 monoclonal antibody [43] have been confirmed to improve the prognosis of PCP infection. For HIV negative patients with PCP, in addition to the extensive antifungal therapy, it may be a new treatment strategy to adjust immune disorders and attenuate excessive inflammatory response.

There were several limitations to this study. First, it was a single site study. Secondly, autoimmune diseases are predominant underlying conditions among our study patients. Studies of HIV negative PCP patients with other underlying disorders such as organ transplant may differ from our findings. Thirdly, follow-up results beyond 3 months are not available, we are unable to know the long-term outcome of this patient cohort. Anyway, our study gave the evidence of the correlation between 
lymphocyte subsets and short term prognosis among these HIV negative PCP patients, our findings suggest lower CD8+ T cell count is independent risk factor for mortality, and in addition to effective anti-fungal therapy, further treatment aiming at regulating immune function should be investigated.

\section{Conclusion}

In conclusion, the immunity process of $P$. jirovecii infection in human body is complex and crucial. Low CD4+ T cell, CD8+ T cell and NK cell counts were related to poor prognosis of PCP in HIV negative patients, and the presence of CD8 $+\mathrm{T}$ cell count below $300 / \mu \mathrm{L}$ was an independent predictor for death. Thus, we proposed that clinicians can use lymphocyte subsets to identify potential patients and make clinical decisions, such as adjusting immunosuppressive regimen and choosing appropriate patient monitoring level.

\section{Abbreviations}

BAL: bronchoalveolar lavage; CI: confidence intervals; $\mathrm{Ct}$ : cycle threshold; D(A-a)O2: alveolar-arterial oxygen difference; FRET: fluorescence resonance energy transfer; GMS staining: Grocott's methenamine silver staining; CXCL 10: chemokine ligand-10; CS: corticosteroid; HAART: highly active antiretroviral therapy; HIV: human immunodeficiency virus; HR: hazard ratio; ICU: Intensive Care Unit; IRB: Institutional Review Board; IRD: immune restoration disease; LDH: lactate dehydrogenase; MV: mechanical ventilation; mtLSUrRNA: mitochondrial large 
subunit rRNA; MSG: major surface glycoprotein; NK cells: natural killer cells; OIs: opportunistic infections; OR: odds ratio; $\mathrm{PaO} 2$ : arterial partial pressure of oxygen; $P$. jirovecii: pneumocystis jirovecii; PCR: polymerase chain reaction; PCP: Pneumocystis peumonia; TMP/SMZ: trimethoprim-sulfamethoxazole; $\beta D G$ : $1,3-\beta-\mathrm{D}$-glucan.

\section{Ethics approval and consent to participate}

The present study was reviewed and approved by the Institutional Review Board (IRB) of Peking Union Medical College Hospital. The IRB waived the requirement to obtain informed consent from each patient because the study met the IRB's minimal risk waiver criteria. We declare that all methods were carried out in accordance with relevant guidelines and regulations.

\section{Consent for publication}

Not applicable.

\section{Availability of data and materials}

The datasets used and/or analysed during the current study are available from the corresponding author on reasonable request.

\section{Competing interests}

The authors declare that they have no competing interests. 


\section{Funding}

This research did not receive any specific grant from funding agencies in the public, commercial, or not-for-profit sectors.

\section{Authors' contributions}

FJ and JX were responsible for study conceptualization. FJ wrote the draft manuscript. JX and HW revised the manuscript.

\section{Acknowledgements}

Not applicable.

\section{Author details}

${ }^{1}$ Dept. of Infectious Diseases, Peking Union Medical College Hospital, Chinese Academy of Medical Sciences \& Peking Union Medical College, Beijing, China.

${ }^{2}$ Clinical Pharmacology Research Center, Peking Union Medical College Hospital, Chinese Academy of Medical Sciences \& Peking Union Medical College, Beijing, China.

\section{References}

[1] Kovacs JA, Masur H, Evolving Health Effects of Pneumocystis One Hundred Years of Progress in Diagnosis and Treatment, JAMA, 301 (2009) 2578-2585. 
[2] Sepkowitz, Kent A, Opportunistic Infections in Patients with and Patients without Acquired Immunodeficiency Syndrome, Clin Infect Dis. 34 (2002) 1098-1107.

[3] Tasaka S, Tokuda H, Pneumocystis jirovecii pneumonia in non-HIV-infected patients in the era of novel immunosuppressive therapies, J Infect Chemother. 18 (2012) 793-806.

[4] Thomas CF, Limper AH, Pneumocystis Pneumonia, NEJM, 350 (2004) 2487-2498.

[5] Mansharamani NG, Balachandran D, Vernovsky I, Garland R, Koziel H, Peripheral blood CD4+ T-lymphocyte counts during Pneumocystis carinii pneumonia in immunocompromised patients without HIV infection, Chest, 118 (2000) 712-720.

[6] Wickramasekaran RN, Jewell MP, Sorvillo F, Kuo T, The changing trends and profile of pneumocystosis mortality in the United States, 1999-2014, Mycoses, 60 (2017) 607-615.

[7] Mori S, Sugimoto M, Pneumocystis jirovecii infection: An emerging threat to patients with rheumatoid arthritis, Rheumatology, 51 (2012) 2120-2130.

[8] Ward M M , Donald F, Pneumocystis carinii pneumonia in patients with connective tissue diseases: the role of hospital experience in diagnosis and mortality, Arthritis Rheum. 42 (1999) 780-789.

[9] Catia Cillóniz, Cristina Dominedò, Míriam J Álvarez-Martínez, Asunción Moreno, Felipe García, Antoni Torres, José M Miro, Pneumocystis pneumonia in the twenty-first century: HIV-infected versus HIV-uninfected patients. Expert Rev Anti Infect Ther. 17 (2019) 787-801.

[10] Beck JM, Harmsen AG, Lymphocytes in host defense against Pneumocystis carinii, Semin Respir Infect. 13 (1998) 330-338.

[11] Gigliotti F, Wright TW, Immunopathogenesis of Pneumocystis carinii pneumonia. 
Expert Rev Mol Med. 7 (2005) 1-26.

[12] Appay V,van Lier RA,Sallusto F, Phenotype and function of human T lymphocyte subsets: consensus and issues, Cytometry A, 73 (2008) 975-983.

[13] McKinley L, Logar AJ, McAllister F, Zheng M, Steele C, Kolls JK. Regulatory T cells dampen pulmonary inflammation and lung injury in an animal model of pneumocystis pneumonia. J Immunol. 2006;177(9):6215-6226.

[14] Opata MM, Hollifield ML, Lund FE, et al. B lymphocytes are required during the early priming of $\mathrm{CD} 4+\mathrm{T}$ cells for clearance of Pneumocystis infection in mice. $\mathrm{J}$ Immunol. 2015;195:611-620.

[15] Alanio A, Hauser PM, Lagrou K, Melchers WJ, Helweg-Larsen J, Matos O, et al, ECIL guidelines for the diagnosis of Pneumocystis jirovecii pneumonia in patients with haematological malignancies and stem cell transplant recipients. J Antimicrob Chemother, 71 (2016) 2386-2396.

[16] Jin F, Liu XH, Chen WC, Fan ZL, Wang HL. High initial $(1,3)$ Beta-d-Glucan concentration may be a predictor of satisfactory response of c aspofungin combined with TMP/SMZ for HIV-negative patients with moderate to severe Pneumocystis jirovecii pneumonia. Int J Infect Dis. 2019;88:141-148.

[17] Ali T., Kaitha S., Mahmood S., Ftesi A., Stone J., Bronze M.S. Clinical use of anti-TNF therapy and increased risk of infections. Drug Healthc Patient Saf. 2013;5:79-99.

[18] Kumar SD, Krieger BP, CD4 lymphocyte counts and mortality in AIDS patients requiring mechanical ventilator support due to Pneumocystis carinii pneumonia, Chest, 113 (1998) 430-433.

[19] Colford JM Jr, Segal M, Tabnak F, Chen M, Sun R, Tager I, Temporal trends and factors associated with survival after Pneumocystis carinii pneumonia in California, 
1983-1992, Am J Epidemiol. 146 (1997) 115-127.

[20] Dworkin MS, Hanson DL, Navin TR, Survival of patients with AIDS, after diagnosis of Pneumocystis carinii pneumonia, in the United States, J Infect Dis. 183 (2001) 1409-1412.

[21] Walzer PD, Evans HE, Copas AJ, Edwards SG, Grant AD, Miller RF. Early predictors of mortality from Pneumocystis jirovecii pneumonia in HIV-infected patients: 1985-2006, Clin Infect Dis. 46 (2008) 625-633.

[22] Fei MW, Kim EJ, Sant CA, Jarlsberg LG, Davis JL, Swartzman A, Huang L, Predicting mortality from HIV-associated Pneumocystis pneumonia at illness presentation: an observational cohort study, Thorax, 64 ( 2009) 1070-1076.

[23] Liu CJ, Lee TF, Ruan SY, Yu CJ, Chien JY, Hsueh PR, Clinical characteristics, treatment outcomes, and prognostic factors of Pneumocystis pneumonia in non-HIV-infected patients, Infect Drug Resist. 12 (2019) 1457-1467.

[24] Freiwald T, Büttner S, Cheru NT, Avaniadi D, Martin SS, Stephan C, et al, CD4+ $\mathrm{T}$ cell lymphopenia predicts mortality from Pneumocystis pneumonia in kidney transplant patients, Clin Transplant, 34 (2020) e13877.

[25] Li Y, Ghannoum M, Deng C, Gao Y, Zhu H, Yu X, Lavergne V, Pneumocystis pneumonia in patients with inflammatory or autoimmune diseases: Usefulness of lymphocyte subsets, Int J Infect Dis, 57 (2017) 108-115.

[26] Blanco JL, Garcia ME, Immune response to fungal infections, Vet Immunol Immunopathol. 125 (2008) 47-70.

[27] Wright TW, Pryhuber GS, Chess PR, Wang Z, Notter RH, Gigliotti F, TNF receptor signaling contributes to chemokine secretion, inflammation, and respiratory deficits during Pneumocystis pneumonia, J Immunol. 172 (2004) 2511-21.

[28] Gigliotti F, Wright TW, Immunopathogenesis of Pneumocystis carinii pneumonia, 
Expert Rev Mol Med. 7 (2005) 1-16.

[29] Park SJ, Hughes MA, Burdick M, Strieter RM, Mehrad B, Early NK cell-derived interferon-gamma is essential to host defense in neutropenic invasive aspergillosis, $\mathrm{J}$ Immunol. 182 (2009) 4306-4312.

[30] Guan H, Moretto M, Bzik DJ, Gigley J, Khan IA, NK cells enhance dendritic cell response against parasite antigens via NKG2D pathway, J Immunol. 179 (2007) 590-596.

[31] Noval Rivas M, Hazzan M, Weatherly K, Gaudray F, Salmon I, Braun MY, NK cell regulation of CD4 T cell-mediated graft-versus-host disease, J Immunol. 184 (2010) 6790-6798.

[32] Bihl F, Germain C, Luci C, Braud VM, Mechanisms of NK cell activation: CD4(+) T cells enter the scene, Cell Mol Life Sci, 68 (2011) 3457-3467.

[33] Kelly MN, Zheng M, Ruan S, Kolls J, D'Souza A, Shellito JE, Memory CD4+ T cells are required for optimal NK cell effector functions against the opportunistic fungal pathogen Pneumocystis murina, J Immunol, 190 (2013) 285-295.

[34] Tadros S, Teichtahl AJ, Ciciriello S, Wicks IP, Pneumocystis jirovecii pneumonia in systemic autoimmune rheumatic disease: A case-control study, Semin Arthritis Rheum. 46 (2017) 804-809.

[35] Gagnon S, Boota AM, Fischl MA, Baier H, Kirksey OW, La Voie L, Corticosteroids as adjunctive therapy for severe Pneumocystis carinii pneumonia in the acquired immunodeficiency syndrome. A double-blind, placebo-controlled trial, $\mathrm{N}$ Engl J Med. 323 (1990) 1444-1450.

[36] Fujikura Y, Manabe T, Kawana A, Adjunctive Corticosteroids for Pneumocystis jirovecii Pneumonia in Non-HIV-infected Patients:A Systematic Review and Meta-analysis of Observational Studies, Arch Bronconeumol. 53 (2017) 55-61. 
[37] Kelly MN, Shellito JE, Current understanding of Pneumocystis immunology, Future Microbiol. 5 (2010) 43-65.

[38] Hori S, Carvalho TL, Demengeot J, CD25+CD4+ regulatory T cells suppress CD4+ T cell-mediated pulmonary hyperinflammation driven by Pneumocystis carinii in immunodeficient mice, Eur J Immunol. 32 (2002) 1282-1291.

[39] Shimizu K, Asakura M, Fujii S, Prolonged antitumor NK cell reactivity elicited by CXCL10-expressing dendritic cells licensed by CD40L+CD4+ memory T cells, J Immunol. 186 (2011) 5927-5937.

[40] Oz HS, Hughes WT, Rehg JE, Thomas EK, Effect of CD40 ligand and other immunomodulalors on Pneumocytis carinii infection in rat model, Microb Pathog. 29 (2000) 187-190.

[41] Wiley JA, Harmsen AG, CD40 ligand is required for resolution of Pneumocystis carinii pneumonia in mice, J Immunol. 155 (1995) 3525-3529.

[42] Zheng M, Shellito JE, Marrero L, Zhong Q, Julian S, Ye P, et al, CD4+ T cell-independent vaccination against Pneumocystis carinii in mice, J Clin Invest. 108 (2001) 1469-1474.

[43] Bhagwat SP, Wright TW, Gigliotti F, Anti-CD3 Antibody Decreases Inflammation and Improves Outcome in a Murine Model of Pneumocystis Pneumonia, J Immunol. 184 (2010) 497-502. 
Figures
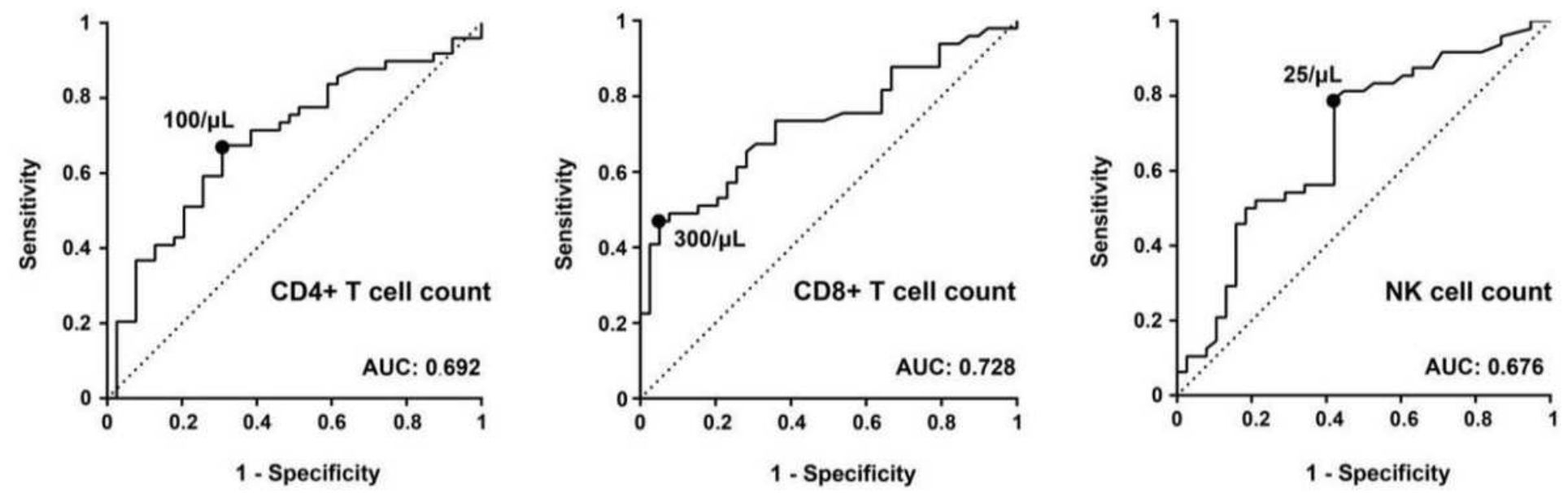

Figure 1

ROC curves for the predictors of in-hospital mortality for CD4+T, CD $8+T$, andNKcellcounts.
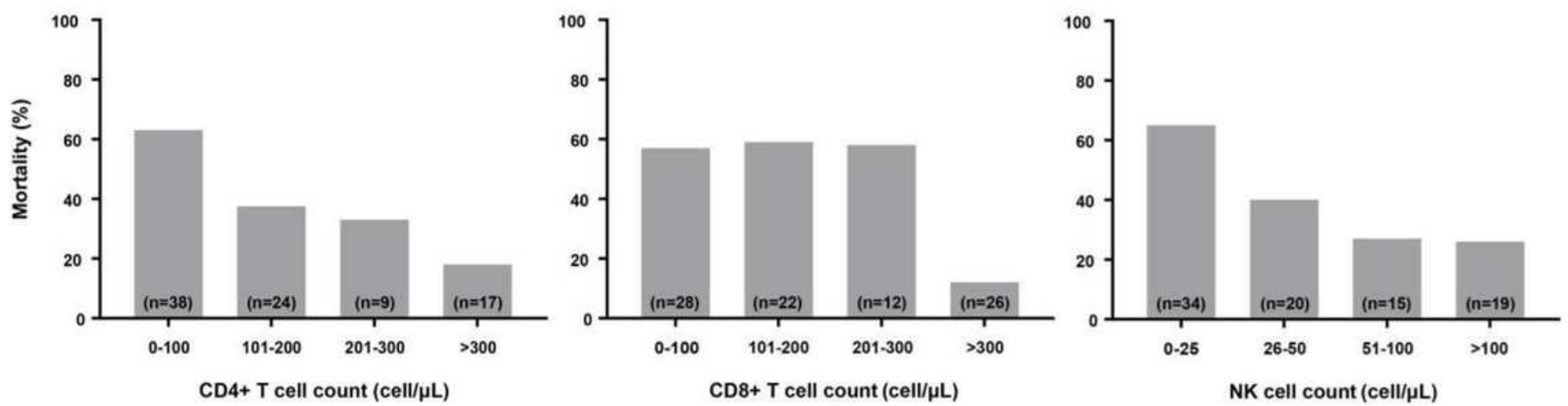

Figure 2

The 3-month mortality rates determined according to the levels of CD4+ T, CD8+T,andNKcellcountsoverdifferentranges. 


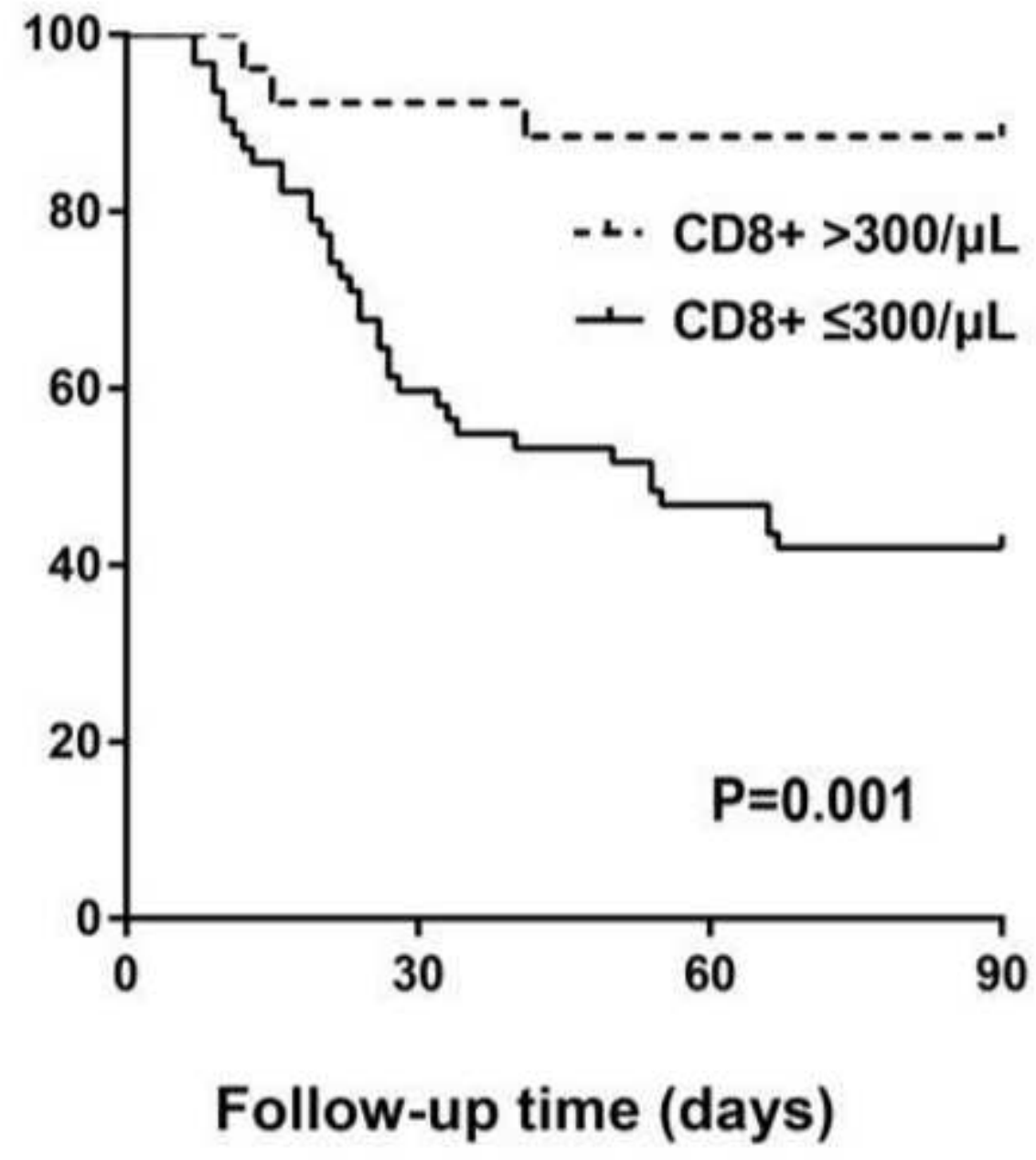

Figure 3

Survival curve for the Cox regression hazards model for the relationship betweenCD8+Tcellcountand3monthmortality. 